\title{
Recepção das ações do Instituto Agronômico de Pernambuco por agricultores de São Bento do Una, Pernambuco
}

\section{Receipt of the actions of the Agronomic Institute of Pernambuco by farmers of São Bento do Una, Pernambuco, Brazil}

\author{
Mízia Fabiana Moreira Barbosa Lopes ${ }^{1}$; Jakes Halan de Queiroz Costa ${ }^{2}$; Tânia Marta Carvalho dos Santos ${ }^{3}$; \\ Conceição Maria Dias Lima ${ }^{4}$ José Cândido Barbosa Lopes ${ }^{5}$
}

${ }^{1}$ Zootecnista graduada pela Universidade Federal de Alagoas, Rio Largo, Alagoas, Brasil. E-mail: mizia fabiana@ hotmail.com. ${ }^{2}$ Prof. Dr. do Centro de Ciências Agrárias da Universidade Federal de Alagoas, Rio Largo, Alagoas, Brasil, e-mail: jakes.sociorural@gmail.com. ${ }^{3}$ Profa. Dra. do Centro de Ciências Agrárias da Universidade Federal de Alagoas, Rio Largo, Alagoas, Brasil, e-mail: taniamarta2@gmail.com. ${ }^{4}$ Profa. Dra. da Universidade Estadual de Alagoas, Delmiro Gouveia, Alagoas, Brasil. E-mail: ceicadias@yahoo.com. ${ }^{5}$ Coordenador do curso de Agroecologia na Escola Técnica Estadual Governador Eduardo Campos, São Bento do Una, Pernambuco, Brasil, e-mail: jcandinho60@gmail.com

\begin{tabular}{l}
\hline A R T I G O \\
\hline Recebido: 04/11/2019 \\
Aprovado: 19/11/2019 \\
\hline Palavras-chave: \\
Agricultura familiar \\
Soberania alimentar \\
Extensão rural \\
Assistência técnica \\
\end{tabular}

Key words:

Family farming

Food sovereignty

Rural extension

Technical assistance

\section{R E S U M O}

A produção de alimentos está sendo muito discutida mundialmente, tanto no que diz respeito ao aumento da produtividade para atender as necessidades da crescente população como também à qualidade desses alimentos. As pequenas propriedades agrícolas são encarregadas de produzir para a maioria da população e para própria subsistência familiar. Objetivou-se com o presente trabalho revelar a importância das ações de Assistência Técnica e Extensão Rural (ATER) para permanência de pequenos agricultores no campo, devido ao seu papel na produção de alimentos e na geração de emprego. O estudo foi realizado no município de São Bento do Una/Pernambuco, o qual recebe assistência técnica do Instituto Agronômico de Pernambuco (IPA). Foram feitas entrevistas com roteiro semiestruturado aos agricultores familiares e aos técnicos do IPA, além de observações diretas englobando dados qualitativos e quantitativos. Foi percebida uma necessidade de maior atenção do governo, com mais políticas públicas para que os serviços, projetos e programas possam ser melhores desenvolvidos. Nesse sentido, os agricultores familiares necessitam de ações de ATER mais efetivas e que tragam melhores condições de trabalho e desenvolvimento para o meio rural do município.

A B S T R A C T
Food production is being widely discussed worldwide, both in terms of increasing productivity to
meet the needs of the growing population and also in terms of the quality of these foods. Small
farms are responsible for producing for the majority of the population and for their own family
subsistence. The objective of this study was to reveal the importance of Technical Assistance and
Rural Extension (ATER) actions for small farmers to remain in the countryside, due to their role
in food production and job creation. The study was carried out in the municipality of São Bento
do Una/Pernambuco, which receives technical assistance from the Agronomic Institute of
Pernambuco (IPA). Interviews with semi-structured script were carried out with family farmers
and IPA technicians, in addition to direct observations covering qualitative and quantitative data.
There was a need for greater government attention, with more public policies so that services,
projects and programs can be better developed. In this sense, family farmers need more effective
ATER actions that bring better working and development conditions to the rural areas of the
municipality.
(2010), as crises mundiais recentes revelam uma vulnerabilidade do sistema agroalimentar em sua missão de oferecer alimentos em quantidade e qualidade para a população mundial.

\section{INTRODUÇÃO}

Existe uma longa discussão no mundo sobre a produção de alimentos e com tudo relacionado a ela ganhando cada vez mais importância com o passar do tempo. De acordo com Marques

\section{Revista Verde}

ISSN 1981-8203

Pombal, Paraíba, Brasil v. 14, n.5, Edição Especial, p.617-624, 2019

doi: $10.18378 /$ rvads.v14i5.7568 
A agricultura familiar se refere a produção agropecuária feita por proprietários de pequenas áreas rurais, cuja mão de obra é basicamente realizada pela família do produtor, e, eles não só são responsáveis por produzirem alimentos para subsistência da unidade familiar, como também para toda a população, uma vez que, a agricultura patronal que é caracterizada por médias ou grandes propriedades com trabalhadores fixos ou temporários cultivam monoculturas com objetivos estritamente comerciais, em especial exportações (PORTUGAL, 2004).

No espaço físico rural, considerado um local diferenciado, onde se vive particularidades do modo de vida e referência identitária do homem rural, ocorre a sua inserção na sociedade nacional como um conjunto de sujeitos sociais, identificados por uma vivência geracional, que vai (re)definindo trajetórias e consolidando projetos emancipatórios de transformação social, de valores e ambiental, ou seja, a agricultura familiar tem importância fundamental no desenvolvimento sustentável ambiental, social e econômico do mundo (WANDERLEY, 2013).

Segundo Caporal (2007), a agricultura familiar além de ser responsável pela maior parte da produção de alimentos, também é capaz de desenvolver processos de construção que criam novas estratégias de desenvolvimento rural sustentável, pela existência de um tecido social rural particular. Este tipo de agricultura justifica a necessidade de serviços públicos de ATER, devido às suas necessidades objetivas e a sua importância socioeconômica, destacando seu papel influente nas estratégias para promoção de cultivos variados e ecológicos, capazes de promover, essencialmente, a segurança e soberania alimentar de toda população.

Porém, no Brasil, a agricultura familiar ainda necessita de informações e de assistência técnica para conseguirem acessar as políticas públicas, que são ferramentas fundamentais para aumentar e qualificar mais a sua produção (SOUZA et al., 2011).

O Instituto Agronômico de Pernambuco (IPA) vinculado à Secretaria de Agricultura e Reforma Agrária (SARA) investe no fortalecimento da agricultura familiar do estado pernambucano, contribuindo para o desenvolvimento rural e sustentável, elevando as condições de vida da sociedade com o aproveitamento racional e equilibrado das potencialidades naturais, buscando garantir a continuidade na renovação dos recursos renováveis e procurando assegurar a perenidade do fundo de fertilidade e o equilíbrio dos ecossistemas (IPA, 2018).

O município de São Bento do Una está localizado na mesorregião do Agreste Pernambucano e conforme o censo agropecuário de 2017 tem 10.535 (dez mil quinhentas e trinta e cinco) pessoas em estabelecimentos agropecuários, das quais 8.859 (oito mil oitocentos e cinquenta e nove) possui laço de parentesco com o produtor, o que representa que a maioria das propriedades rurais são de agricultura familiar (IBGE, 2017).

Exposta essa discussão e o desencontro entre a inclinação mundial e a recente diminuição da importância dada ao setor de produção de alimentos que proporciona a soberania alimentar no Brasil, o objetivo do presente estudo foi analisar a importância das ações do Instituto de Pesquisa Agronômica de Pernambuco como ferramenta de acesso as políticas públicas pelos agricultores familiares do município de São Bento do Uma, Pernambuco.

\section{MATERIAL E MÉTODOS}

O trabalho é um estudo descritivo (GIL, 2007; YIN, 2010; STAKE, 1994), com o qual se procurou conhecer a realidade de vida dos agricultores atendidos pela Estação Experimental do IPA, - São Bento do Una - PE, localizada na estrada para Capoeiras, km 03, no período de março a maio de 2019, no acima citado município que está localizado na Micro-região do Vale do Ipojuca, Meso-região do Agreste. O município possui Latitude: $08^{\circ} 31^{\prime} 12^{\prime \prime}$, Longitude: $36^{\circ} 33^{\prime} 00^{\prime \prime}$ e altitude de $650 \mathrm{~m}$. A área é de aproximadamente $713 \mathrm{Km}^{2}$ com clima semi-árido e vegetação de Caatinga (SÃO BENTO DO UNA, 2015).

Foram coletados dados secundários sobre a região em estudo, como dados do município (IBGE, 2017) e observações diretas para fazer a primeira leitura das informações do ambiente. Em seguida foi traçado um perfil da referida comunidade.

Foram estudados os aspectos socioeconômicos: escolaridade, composição da renda familiar, disponibilidade de água, iluminação pública, estradas, saúde, educação, produção e comercialização da produção, características da moradia, transporte utilizado na comercialização dos produtos agropecuários, formas de comercialização, condições das estradas, culturas plantadas, faixa etária dos agricultores e os principais problemas enfrentados por eles, bem como a recepção e percepção das ações de ATER.

$\mathrm{Na}$ sequência foram realizadas entrevistas semiestruturadas, seguindo um roteiro de perguntas, utilizando a amostragem aleatória simples (M.A.S.), composta por 30 (trinta) agricultores familiares, atendidos pela Estação Experimental do IPA e dois técnicos de ATER do Instituto, durante as visitas no campo, em feiras de agricultura familiar e no escritório da Estação Experimental do IPA. A amostra foi definida de acordo com os critérios preconizados por Minayo (2010), assim como, o dimensionamento da quantidade de entrevistas seguiu o critério de saturação, entendido como conhecimento formado pelo pesquisador de que compreendeu a lógica interna do grupo ou da coletividade, no caso os agricultores familiares e suas interações com demais atores sociais. Todos os entrevistados concordaram em participar da pesquisa, tendo assinado um termo de consentimento, embora tiveram a identidade preservada.

As respostas obtidas por meio dos questionários foram agrupadas em categorias e tratadas por meio da análise de conteúdo a partir do estabelecimento do princípio de classificação, conforme Bardin (2011) recomenda, permitindo tomar decisões e tirar conclusões a partir da organização dos mesmos. Os dados foram tabulados em planilhas eletrônicas (Excel) e organizados em gráficos.

\section{RESULTADOS E DISCUSSÃO}

A distribuição por gênero dos entrevistados (figura 1) indicou uma quantidade superior de homens (57\%) em relação às mulheres $(43 \%)$. Esses resultados se aproximam dos obtidos em outros estudos sobre a realidade brasileira no meio rural, onde a figura masculina é predominante, o que evidencia a existência de uma estrutura patriarcal, em que não ocorre a participação das mulheres nos processos decisórios do cotidiano (COSTA, 2016). 
Figura 1. Distribuição conforme gênero dos agricultores familiares atendidos pelo Instituto Agronômico de Pernambuco em São Bento do Una, Pernambuco

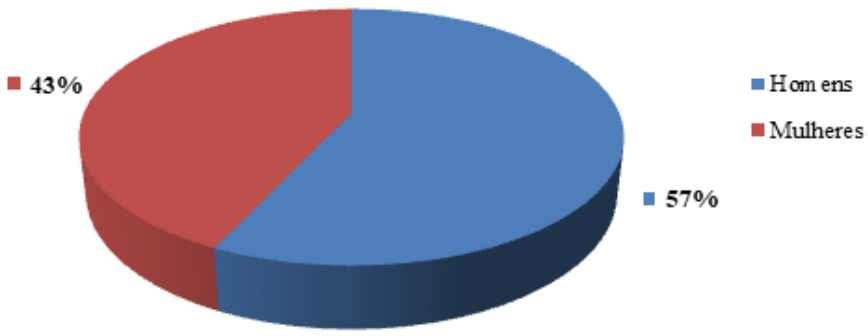

A faixa etária dos pequenos produtores é bem diversificada, a figura 2 ilustra a porcentagem de homens e mulheres acima e abaixo de 40 anos. Todos os agricultores em questão, confirmaram viver no campo desde criança. Foi observado também que esses agricultores, em sua maioria, permanecem no meio rural porque gostam do campo ou porque constituíram famílias com produtores. Apenas uma minoria disse permanecer no campo por falta de opção de trabalho. Diante desse contexto, vemos o recente cenário do meio rural que foi encontrado também em pesquisa feita pelo MDA (2016)

Figura 2. Distribuição conforme idade dos agricultores familiares atendidos pelo Instituto Agronômico de Pernambuco em São Bento do Una, Pernambuco

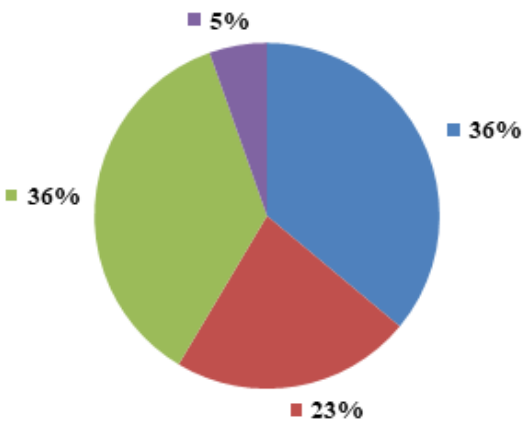

- Mulheres até 40 anos

- Mulheres abaix o de 40 anos

Hom ens até 40 anos

- Hom ens abaix o de 40 anos

Os dados relacionados à escolaridade estão dispostos na figura 3, mostrando que quase $50 \%$ (cinquenta por cento) dos produtores não concluíram o ensino fundamental e apenas $17 \%$ (dezessete por cento) concluíram o ensino médio. Contudo, o nível de analfabetismo é baixo, representando somente $7 \%$ (sete por cento).

Provavelmente, a quantidade de agricultores que não conseguiram concluir o nível fundamental se deve as dificuldades diárias de cada um deles, uma vez que a escolaridade é influenciada pelo ser e estar das pessoas. Os maiores níveis de escolaridade são de fundamental importância para que o homem do campo tenha o poder de assimilar as inovações técnico-científicas proporcionando melhorias nas suas formas de reprodução social. Salientando que de acordo com os dados coletados a maioria dos agricultores familiares do município de São Bento do Una não completou o ensino fundamental. Esse cenário do nível de educação reforça o que afirmou Lira et al. (2013), "no Brasil, o nível de escolaridade entre os pequenos agricultores encontra-se em torno de 3, 4 anos, o que equivale ao nível fundamental incompleto."

Figura 3. Distribuição conforme a escolaridade dos agricultores familiares atendidos pelo Instituto Agronômico de Pernambuco em São Bento do Una, Pernambuco.

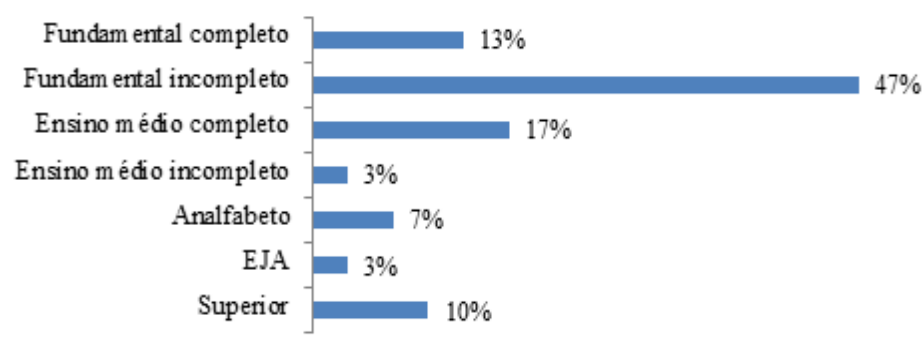

A maioria dos pequenos produtores possui de 1 a 4 filhos, os quais tem acesso a escolas municipais, a maioria na própria zona rural, e, estaduais na zona urbana. Alguns agricultores com filhos adultos relataram que gostariam que os mesmos estivessem com eles, seria mais pessoas para mão de obra e de grande ajuda no trabalho difícil. Porém, foram tentar algo "melhor na cidade", mas dizem não ser fácil e consideram ilusão.

"Aqui na roça tem prato cheio, acima de tudo. [...]. Criei meus quatro filhos e gostaria que eles tivessem ficado no campo. Só um casou e mora no sítio vizinho. Uma vive lutando em Belo Jardim (cidade vizinha) querendo ser enfermeira, lutou bastante pra conseguir ser técnica e agora quer fazer superior. Os outros dois estão em São Paulo, mas lá tudo é mais caro, é ilusão melhorar de vida lá. Tudo é mais caro, paga aluguel, tudo longe. Aqui tem casa, tem comida que nós planta e dá pra se virar, é só ter coragem de trabalhar, até a energia é mais barata aqui porque é rural." (Entrevista, 1).

Enquanto outros preferem que eles busquem "crescimento" na cidade e lutam para que eles consigam formação superior para melhorar de vida.

"Eu sei lá, estou desanimada, sete anos de seca. Gosto muito do campo, me criei aqui. Mas, sempre produzimos pra consumo. Meu sonho era produzir hortaliça, mas não tem água. Tenho sete filhos $e$ não tem o que fazer, a gente vive com a cesta (mantimentos) que a associação dá, de vez em quando, e da minha aposentadoria. [...]. Eles estudam, tem que estudar pra ver se consegue alguma coisa melhor. Espero que eles consigam alguma coisa na cidade pra melhorar um pouco." (Entrevista, 28).

Almejando outras atividades ocupacionais os jovens deixam a propriedade, confirmando a afirmação de Abramovay 
et al. (1998), de que o êxodo rural nas regiões de predomínio da agricultura familiar atinge as populações mais jovens com muito mais ênfase. Sendo assim, provocando mudanças nas percepções sobre a ocupação agrícola, permitindo que as situações da vida agrícola, antes consideradas como normais e naturais, dessem lugar a uma comparação capaz de levar os agricultores, especialmente os com menos condições econômicas, a se auto perceberem como um grupo desfavorecido em relação aos demais.

A habitação foi avaliada através das observações diretas no momento das visitas, as quais são todas casas de alvenaria e possuem televisão, antena parabólica e internet.

No que diz respeito à água, em algumas localidades que não tem abastecimento ou poços o Poder Público envia caminhões pipa para encherem as cisternas dos mais necessitados enquanto outros agricultores mais estruturados compram sua própria água.

A energia está presente em todas as localidades da zona rural visitada, porém, é monofásica na região do Sítio Tamanduá que se localiza na Serra da Macambira, região responsável pela produção agrícola do município, a energia nesse caso, se torna uma limitante para utilização de bombas de irrigação, uma vez que nesta região tem água de poços, sendo mais uma dificuldade para a cadeia produtiva.

As estradas possuem condições razoáveis de trânsito, mas, segundo agricultores da Associação dos Pequenos Agricultores do Sítio Jequirí e Adjacências, o acesso nem sempre é bom, pouco antes da visita foi feita manutenção. Na Vila do Espirito Santo, região responsável pela produção pecuária do município e onde se encontram outros sítios, associações e assentamentos, as vias de acesso são de boa conservação.

Esses aspectos socioeconômicos também foram identificados no relatório analítico realizado pelo MDA (2016) no Território Rural do Agreste Meridional de Pernambuco, o qual indica um ICV (índice de condições de vida) com valor médio, correspondente a uma percepção de melhora na qualidade de vida dos entrevistados. Ainda segundo o MDA (2016) a situação econômica, juntamente com as condições de alimentação e nutrição, revela um grau de satisfação médio alto dos entrevistados. No entanto, apesar dessa satisfação, a permanência dos familiares no domicílio foi o indicador mais baixo dessa instância. Uma hipótese para essa evasão pode ser a atratividade das cidades, tanto nas atividades de lazer quanto na expectativa de melhores condições de trabalho.

Quanto ao primeiro acesso aos serviços do IPA (Figura 4), o levantamento mostrou que este ocorreu através da escola técnica, prefeitura e convite dos próprios técnicos de assistência técnica e extensão rural (ATER), e principalmente, através de associações rurais. As associações rurais são criadas para assegurar os direitos básicos de cidadania, visando o desenvolvimento rural, quando persiste a falta de poder dos pequenos agricultores para influenciar nas políticas públicas (ANJOS, 2007). Neste cenário, vemos representatividade no auxílio para acesso ao setor público.

A produção agrícola é voltada para as culturas de subsistência, tais como milho, mandioca, feijão e alguns criam vaca de leite, gado de corte e pequenos animais como caprinos, ovinos e suínos.
Figura 4. Distribuição dos agricultores familiares conforme o primeiro acesso ao Instituto Agronômico de Pernambuco em São Bento do Una, Pernambuco.
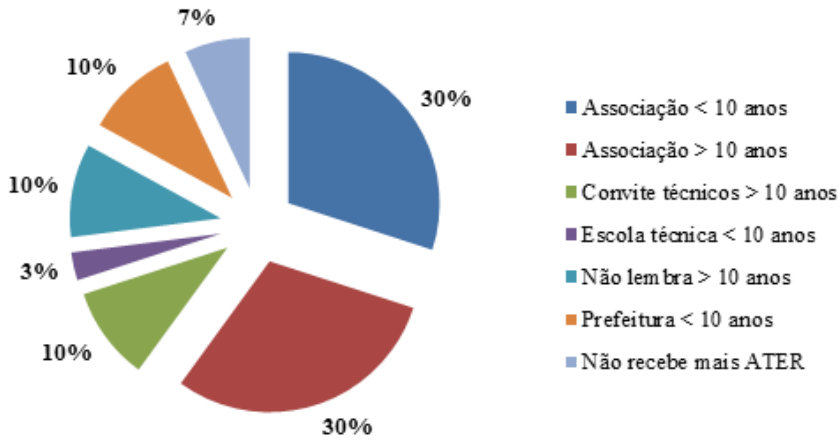

Na composição da renda familiar, muitos são aposentados ou recebem auxílio de programas do governo como Bolsa Família, que foi criado em 2003 e beneficia aproximadamente 14 milhões de famílias em todos os municípios brasileiros, sob a gestão nacional do Ministério do Desenvolvimento Social e Combate à Fome (MDS), o programa vem contribuindo para a redução da desigualdade em nosso país.

Os programas sociais do governo são muito importantes para os agricultores e o Bolsa Família, por ser um programa de transferência direta de renda, direcionado às famílias em situação de pobreza e de extrema pobreza em todo o País, também fazem parte da realidade de alguns produtores rurais, de modo que conseguem superar a situação de vulnerabilidade durante o período de seca. O programa busca garantir a essas famílias o direito à alimentação e o acesso à educação e à saúde (CEF, 2019).

Outros agricultores buscam complementar sua renda com trabalhos fora do campo, os quais incluem prestação de serviços públicos e autônomos. Os mais necessitados irão receber o fomento via Programa Dom Hélder Câmara, o qual tem como objetivo principal reduzir e erradicar a pobreza rural e as desigualdades do semiárido, mitigando os efeitos causados pelas condições climáticas adversas, por meio da integração de políticas públicas federais, estaduais e municipais. O programa Dom Hélder irá ter início a partir do mês de junho do corrente ano, para utilização do recurso na produção agropecuária, melhorando as condições de vida dos agricultores familiares da região.

Fatos esses, evidenciam que a pluriatividade é presente na vida dos agricultores, representando uma alternativa de reprodução social e econômica (SCHNEIDER, 2003), garantindo assim, a sobrevivência para a maioria das famílias dos mesmos.

Salientando ainda, que a maioria dos pequenos produtores participam do Programa Nacional de Fortalecimento da Agricultura Familiar (PRONAF), o qual auxilia no fortalecimento das atividades desenvolvidas pelo produtor familiar, de forma a integrá-lo à cadeia de agronegócios, proporcionando-lhe aumento de renda e agregando valor ao produto e à propriedade, mediante a modernização do sistema produtivo, permitindo a valorização do seu trabalho e sua 
profissionalização, estimulando a geração de renda e melhorando o uso da mão de obra familiar.

Para conseguirem desenvolver suas atividades produtivas além de contar com os seus familiares alguns contam com o auxílio de vizinhos, fazendo uma rotação de plantio entre suas terras, conseguindo uma mão de obra de troca.

\begin{abstract}
"Não sei como ia fazer nesse tempo se não tivesse minha aposentadoria, ela é pouca mais ajuda demais, principalmente nesses últimos nove anos sem chuva. Não dá pra plantar nada, mal dá pra dentro de casa." (Entrevista, 5).

"Sempre faço de tudo, artesanato com pallet, faço bolo vou me virando principalmente no verão, busco sempre pesquisar e me esclarecer na internet para fazer algo novo." (Entrevista, 16).

"Meu marido é motorista e ajuda nas contas de casa, ele não acredita muito no campo. [...]. Eu gosto e é uma coisa que eu preciso me dedicar mais. [...]. O que mais me dói, é não ter uma casa no sítio pra morar e tem tantas que estão fechadas de pessoas que conseguiram com auxílio do governo e eu não consegui." (Entrevista, 17).

"A agricultura é a sobrevivência da minha família, a gente tem que cultivar para nossa sobrevivência. Não tá fácil pra viver em lugar nenhum. [...]. Às vezes zera a produção e não tem o que fazer na cidade, a Bolsa Família ajuda um pouco." (Entrevista, 21).

"Na agricultura temos que observar o que produz no local e se tem valor, se não tiver tem que adaptar. Com todo sacrifício não me vejo sem ela. Com a agricultura tenho liberdade, tenho como crescer. Vivo dela, graças a Deus." (Entrevista, 7).
\end{abstract}

Quanto às ações desenvolvidas pelo IPA os agricultores consideram ser de qualidade e muita importância, apesar de acharem que em tempos atrás era melhor, tinham mais ajuda e apoio. Eles relataram, em grande maioria, que essa baixa nos serviços do Instituto se deve à falta de incentivos (recursos financeiros) do governo. Alguns citaram até nomes de governantes que representaram mais a classe e buscavam sempre melhorar as condições de trabalho, moradia, produção e comercialização.

Dentre as ações desenvolvidas, as que mais citaram foi à distribuição de sementes (feijão, milho, sorgo e palma), a assistência técnica e o auxílio para comercializar os produtos através de feiras de agricultura familiar na região e do Programa de Aquisição de Alimentos (PAA), que compra alimentos produzidos pela agricultura familiar e distribui gratuitamente para pessoas que não têm acesso à alimentação adequada e também para entidades de assistência social (Centro de Referência de Assistência Social - CRAS, por exemplo), para entidades públicas de segurança alimentar e nutricional (como cozinhas comunitárias e restaurantes populares) e para a rede pública e filantrópica de ensino.

Destacando também, a comercialização para o Programa Nacional de Alimentação Escolar (PNAE), que garante o direito humano à alimentação adequada e saudável, de acordo com a Lei $\mathrm{n}^{\mathrm{o}} 11.947$, de 16 de junho de 2009, a qual determina que no mínimo $30 \%$ do valor repassado a estados, municípios e Distrito Federal pelo Fundo Nacional de Desenvolvimento da Educação (FNDE) deve ser destinado ao Programa Nacional de Alimentação Escolar (PNAE) para ser utilizado na compra de gêneros alimentícios diretamente da agricultura familiar e do empreendedor familiar rural ou de suas organizações, priorizando-se os assentamentos da reforma agrária, as comunidades tradicionais indígenas $\mathrm{e}$ as comunidades quilombolas. Logo, visa promover melhores hábitos alimentares e incentivar o comércio e a produção local de alimentos. Contudo, o acesso ao PNAE no período da pesquisa era difícil, pois, exige registros no MAPA e vigilância sanitária para comercialização dos produtos para o programa e os produtores não tinham tais registros e consideram complicado.

Os produtores também comercializam parte da sua produção de forma independente, seja na feira local ou em feiras das cidades vizinhas, mas, consideram melhor comercializar com o apoio do IPA.

"Eu faço polpas e doces com as frutas que eu produzo no sítio, comercializo no comércio da cidade e vou a todos os eventos e feiras agroecológicas que os técnicos do IPA me indicam. Eles ajudam muito na divulgação, no incentivo e apoio para nós agricultores." (Entrevista, 11).

"O PAA que garante a venda e um dinheiro certo. [...]. A agricultura não é valorizada, o que você gasta, você não tira. Aqui no IPA pelo PAA o valor é melhor, aqui eu vendo o quilo da macaxeira por $R \$ 1,88$ se eu for vender a qualquer atravessador da feira eles só pagam R\$1.00.” (Entrevista, 19).

Segundo Grisa et al. (2011), uma ferramenta importante de valorização da produção da agricultura familiar, são os mercados institucionais, que utilizam o poder de compra controlado pelas esferas do governo para aquisição pelo estado dos produtos oriundos dos pequenos agricultores.

Outro relato sobre as ações desenvolvidas pelo órgão de ATER do estado, foi que as mesmas antigamente eram melhores, porque possibilitavam acesso a trator para aração e alguns até receberam animais para iniciarem a produção pecuária.

"Minha "filha", o pessoal do IPA vem aqui há mais de 20 anos. [...]. Antigamente era bem melhor, na época eles começaram a fornecer água, sementes, palma e até aragem. Continua sendo bom, mas era melhor. Hoje eles auxiliam com as sementes, mas não é a quantidade suficiente, e na assistência pra gente plantar. Recomendam não colocar agrotóxicos e fazer tudo natural pra gente vender nas feiras agroecológicas, ajuda no cadastro dos programas do governo (PAA e PNAE), essas coisas." (Entrevista, 1).

"O IPA é muito importante e ajuda bastante, principalmente na pecuária, eles orientam nas 
criações e sementes de qualidade pra plantar. A junção do IPA com a associação foi uma junção perfeita para ajudar a gente do campo." (Entrevista, 8).

"Ajuda muito principalmente na área do PAA se fosse contínuo era bom demais, precisava controlar mais porque tem ano que não tem aí ficamos entregando a mercadoria aos atravessadores que pagam barato." (Entrevista, 25).

As ações citadas pelos entrevistados estão de acordo com a missão do IPA que é gerar e adaptar tecnologia, prestar assistência técnica e extensão rural prioritariamente aos agricultores de base familiar, realizar obras de infraestrutura hídrica e disponibilizar bens e serviços para o desenvolvimento sustentável do agronegócio (IPA, 2008).

Os pequenos produtores esperam que no futuro sejam melhores assistidos pelas políticas públicas, que as ações exercidas pelo Instituto sejam no mínimo como antigamente, possibilitando um auxílio na produção e desenvolvimento das propriedades. Segundo grande parte dos produtores o governo é o principal entrave de melhorias, uma vez que não manda recursos para que sejam feitas. Eles relatam que a necessidade de mais técnicos para assistência, uma distribuição regular e em quantidades suficientes de sementes, bem como formas de comercializar seus produtos a um preço justo são os principais pontos para o sucesso no processo produtivo que consequentemente gera melhores condições de vida para suas famílias.

"Espero que haja uma reestruturação do IPA que nos ajuda muito com a assistência técnica. Eu tinha como optar por empresas privadas, mas com o crédito fundiário do nosso assentamento demos preferência pelo IPA, por ser do município e por atender nossas necessidades. Embora esteja deficiente o quadro de funcionários. " (Entrevista, 12).

"Espero que no futuro tenham mais técnicos, os que têm são abnegados, uma melhora na genética das sementes e animais. Melhorar é sempre preciso e o gargalo de tudo é a comercialização que fica incerta, falta local pra comércio. Espero mais reconhecimento do governo para a agricultura familiar." (Entrevista, 15).

Conforme Pires (2003), a ATER sempre foi movida pela ideia de que o aumento de técnicas de produção modernas resulta em melhorias nas condições de vida das pessoas envolvidas. A Associação Brasileira das Entidades Estaduais Assistência Técnica e Extensão Rural (ASBRAER) considera que os órgãos estaduais de ATER tem uma estrutura que possibilita realizar atendimento bastante significativo de forma individual e coletiva e que pode ser de grande valia para fazer chegar às políticas públicas para os agricultores.

O que se espera, é que todas as esferas do Poder público valorizem essa conjuntura de apoio, como um instrumento de acesso às políticas públicas pelas populações rurais. Sendo assim, conferindo maior importância e uma crescente utilidade para essa rede, através de uma valorização maior, resultando em melhores condições para a sua manutenção. Visto que, os pequenos agricultores consideram que a agricultura é tudo, é fonte de renda, é moradia e disseram não trocar por nada apesar das dificuldades do trabalho pesado, da falta de valorização, da seca que é característica da região, pois, foram criados dela e criam seus filhos também, não precisam ser mandados e podem produzir o próprio alimento.

"É minha renda, toda importância, não faço outra coisa. Eu gosto do que faço me criei no campo." (Entrevista, 10).

“Ave Maria, é fundamental. Se os agricultores não planta, a cidade não janta. Só falta mais valorização." (Entrevista, 11).

"É fundamental, é onde produzimos a nossa alimentação e da população, é tudo, de onde tiro meu sustento. Não me vejo sem ela." (Entrevista, $30)$.

De acordo com o Núcleo de Estudos Agrários e Desenvolvimento Rural (NEAD), do MDA, há muito tempo os agricultores familiares deixavam o meio rural para poder alimentar sua família, hoje em dia eles valorizam o trabalho agrícola e usufrui das condições de subsistência no campo. Aproximadamente $84 \%$ dos jovens agricultores brasileiros não trocam a vida rural pela vida em grandes cidades para buscar oportunidades de trabalho (BRASIL, 2015).

Quanto ao perfil de dois dos três técnicos de ATER que atendem o município, devido o terceiro não ter tido disponibilidade para participar do estudo durante o período da pesquisa, foi visto que ambos possuem o nível médio/técnico e trabalham no instituto, um há nove anos, e o outro há dois anos, desenvolvendo orientações técnicas sobre produção agrícola e animal, comercialização, garantia safra, Pronaf, PAA, Programa Dom Hélder Câmara, distribuição de sementes, mudas e palma forrageira, projetos para assentamentos, organização de feiras de agricultura familiar.

$\mathrm{Na}$ opinião dos profissionais, o desenvolvimento rural do município se encontra lento e acreditam que um dos fatores que contribuíram para esse fato está no longo período sem chuvas. As precipitações pluviais de forma periódica é um dos fatores mais importante na produção agrícola e exerce influência sobre todas as fases da produção agrícola (COSTA et al., 2015).

"A cidade recuou um pouco em termos de desenvolvimento, esse fato aconteceu devido a alguns anos de seca. Esse ano a intenção é dar um maior apoio na produção de forragem e com isso aumentar a produção animal local." (Entrevista, 31).

Os técnicos afirmaram ainda que são procurados pelos agricultores e que quando fazem as visitas técnicas são bem recebidos pelos produtores. O trabalho de ATER é bem aceito, alguns, minoria, resistem as orientações, enquanto outros buscam inovações. Fato este, descrito e observado durante as visitas aos produtores rurais do presente estudo. 
"Os agricultores são bem receptivos e temos um bom entrosamento, eles nos recebem com gratidão e esperança de dias melhores." (Entrevista, 32).

No ponto de vista dos extensionistas, para melhorar e aperfeiçoar as ações desenvolvidas no Instituto é necessário um novo olhar dos governantes para a agricultura familiar, para que assim possam conseguir realizar um trabalho melhor e menos burocrático. Os principais entraves para que possam desenvolver os seus trabalhos são por conta da falta de recursos financeiros que enfraquecem a estrutura física do órgão.

"Precisamos de uma estrutura melhor e uma maior equipe para atender todo o município. Além de recursos financeiros e equipe técnica. Temos muito trabalho para poucos funcionários." (Entrevista, 31).

Declararam também que uma forma de minimizar as dificuldades, não só do IPA, mas também da ATER, é, em primeiro lugar, começar uma restruturação do Instituto. No caso de São Bento do Una ter um escritório na cidade e realizar concurso público para contratação de novos funcionários para preencher a lacuna no quadro de técnicos e dispor de recursos financeiros para implementar as atividades desenvolvidas na região. A Associação Brasileira das Entidades Estaduais de Assistência Técnica e Extensão Rural verificou durante um levantamento do quadro de pessoal dos órgãos estaduais de ATER no ano de 2018 , que $85 \%$ do total de contratados são para região nordeste, devido os órgãos nela localizados sentirem uma carência de pessoal para realizar o atendimento, uma vez que, há um grande contingente de agricultores familiares (ASBRAER, 2018).

"Olha, para minimizar as dificuldades, em minha
opinião, seria o governo olhar para o homem do
campo, já era uma ajuda fundamental. Porque não
temos um escritório na cidade que facilite o acesso
dos agricultores para chegarem até nós, fora à
falta de técnicos para conseguir atender toda a
área, era interessante que tivesse concurso, ainda
existe a falta de recursos para melhorar as
atividades que realizamos no município."
(Entrevista, 32).

Os técnicos consideram que o trabalho que desenvolvem é de grande importância para os agricultores, principalmente os pequenos, pois, assim eles têm acesso à informação, condições de melhorar a renda familiar e comercializar seus produtos através dos programas do governo, como PAA e PNAE que garantem a compra certa e a preço mais justo que o dos atravessadores, como os agricultores relataram acima. Ainda disseram que o acesso às políticas públicas é importante e facilmente conseguido através da ATER.

O papel dos Técnicos Estaduais da Pesquisa e da Extensão consiste em orientar, monitorar e participar dos eventos de capacitação tecnológica, apoiar e ou realizar ações de pesquisa e desenvolvimento que contribuam para o alcance das metas previstas, realizar as avaliações de impacto e analisar seus resultados, para subsidiar a diretoria nas tomadas de decisões que reorientem as ações dos programas, quando necessário, promover as articulações institucionais que garantam as parcerias necessárias à realização integral das ações e apoiar tecnicamente as equipes de elaboração, execução e monitoramento dos macroprogramas (IPA, 2018).

\section{CONCLUSÕES}

Os agricultores têm boa percepção e recepção das ações do IPA e são conscientes do seu papel na economia e sociedade. Entretanto, sentem-se desvalorizados e enfrentam dificuldades para produzir e comercializar seus produtos. Os agricultores se identificam com o campo e possuem esperança de melhorias no futuro que acreditam vir através de políticas públicas.

\section{REFERÊNCIAS}

ABRAMOVAY, R.; SILVESTRO, M. L.; CORTINA, N.; BALDISSERA, I. T.; FERRARI, D. L.; TESTA, V. M. Juventude e agricultura familiar: desafios dos novos padrões. Brasília: Unesco, 1998.

ANJOS, E. Coprasul: Entre o idealizado e o vivido - Uma análise da prática cooperativista no MST. In: DAGNINO, E; PINTO, R. P. (orgs.). Mobilização, participação e direitos. São Paulo: Contexto, 2007. p. 109-127.

BARDIN, L. Análise de conteúdo. São Paulo: Edições 70, 2011. 229 p.

BRASIL. Ministério do Trabalho e Emprego. Agricultura familiar leva dignidade para o campo. 2015. Disponível em: <http://www.brasil.gov.br/economia-

emprego/2015/05/agricultura-familiar-leva-dignidade-para-ocampo>. Acesso em: 06 jun. 2019.

CAPORAL, F. R. (coord.); RAMOS, L. de E. F.; COSTABEBER, J. A.; PAULUS, G.; CAPORAL, D. S. Extensão Rural e Agroecologia: temas sobre um novo desenvolvimento rural, necessário e possível. - Brasília: MDA, 2007. 408 p.: il

CEF. CAIXA ECONOMICA FEDERAL. O que é o Bolsa Família? Disponível em: <http://www.caixa.gov.br/programassociais/bolsa-familia/Paginas/default.aspx >. Acesso em: 26 jun. 2019.

COSTA, A. de S.; OLIVEIRA, V. G. de; PEREIRA, A. R.; BORGES, P. de F.; ARAÚJO, L. de S. Estudo do clima na região do brejo paraibano utilizando técnicas de séries temporais, para previsão com o modelo Sarima. Gaia Scientia, v. 9, n. 1, p. 127 133. 2015.

COSTA, J. H. Q. Processos de Cooperação em Assentamentos Rurais do Litoral Norte do Estado de Alagoas. Tese (Doutorado - Programa de Pós-Graduação em Sistemas de Produção Agrícola Familiar, Faculdade de Agronomia Eliseu Maciel, 
Universidade Federal de Pelotas. UFPEL, Pelotas, 2016. 286f.: il.

GIL, A. C. Como elaborar projetos de pesquisa. - 4.ed. - São Paulo: Atlas, 2007. 176 p.

GRISA, C.; SCHMIT, C. J.; MATTEI, L. F.; MALUF, R. S.; LEITE, S. P. Contribuições do Programa de Aquisição de Alimentos à segurança alimentar e nutricional e à criação de mercados para a agricultura familiar. Agriculturas, v. 8, n. 3, p. 34-41, 2011.

IBGE. Instituto Brasileiro de Geografia E Estatística. Cidades. Disponível em $<$ http://cidades.ibge.gov.br/xtras/perfil.php?lang=\&codmun=61 300\&search=pernambuco|sao-bentodo-uma>. Acesso em: Jan. 2020 .

IPA, Instituto Agronômico de Pernambuco. Apresentação, 2008. Disponível em: <http://www.ipa.br/novo/extensaoapresentacao > Acesso em: 21 mai. 2019.

IPA, Instituto Agronômico de Pernambuco. Plano Anual de Negócios - atualização 2018. Disponível em: <http://www.ipa.br/novo/pdf/plano-anual-negocios-2018.pdf>

Acesso em: 27 mai. 2019.

LIRA, C. C.; QUEIROZ, M. L.; COSTA, C. F. S.; GOMES, R. V. R. S.; COELHO, J.; FERREIRA, K. M.; SAMPAIO, B. O. Perfil socioeconômico de agricultores familiares no município de Barreiros, PE. In: XIII Jornada de Ensino, Pesquisa e Extensão JEPEX, UFPE, 2013.

MARQUES, P. E. M. Embates em torno da segurança e soberania alimentar: estudo de perspectivas concorrentes. Segurança Alimentar e Nutricional, v.17, n.2, p.78-87, 2010.

MINAYO, M. C. de S. O desafio do conhecimento: pesquisa qualitativa em saúde. - 12.ed. - São Paulo: Hucitec, 2010. 407p.

MINISTÉRIO DO DESENVOLVIMENTO AGRÁRIO - MDA. 2016. Relatório Analítico. Território Rural do Agreste Meridional de Pernambuco. Disponível em: <http://sit.mda.gov.br/mapa.php> Acesso em: 05 jun. 2019.

PIRES, M. L. L. e S. A (re)significação da extensão rural. O cooperativismo em debate. In: LIMA, J. R. T. (org.). Extensão rural e desenvolvimento sustentável. Recife: Bagaço, 2003, 4570 .

PORTUGAL, A. D. O Desafio da Agricultura Familiar. In: Embrapa, artigos, 2004.

SÃO BENTO DO UNA. História, Pernambuco. 2015. Disponível <http://www.saobentodouna.pe.gov.br/v1/index.php/conhecasao-bento-do-una/historia>. Acesso em: ago. 2015.
SCHNEIDER, S. Teoria social, agricultura familiar e pluriatividade. Revista Brasileira de Ciências Sociais, v. 18, n. 51, p.99-12, 2003.

STAKE, R. E. Handbook of qualitative research. London: Sage, 1994.

SOUZA, P. M.; FORNAZIER, A.; PONCIANO, N. J.; NEY, M. G. Agricultura familiar versus agricultura não-familiar: uma análise das diferenças nos financiamentos concedidos no período de 1999 a 2009. Documentos Técnicos - Científicos, v. 42, n. 1. 2011.

WANDERLEY, M. N. B. Juventude Rural: vida no campo e projeto para o futuro. Recife: Editora da UFPE, 2013.

YIN, R. K. Estudo de caso: planejamento e métodos. - 4.ed. Porto Alegre: Bookman, 2010. 248p. 